\title{
Sexting Prevalence and Socio-Demographic Correlates in Spanish Secondary School Students
}

\author{
Cristian Molla-Esparza ${ }^{1}$ Emelina López-González ${ }^{1} \cdot$ Josep-María Losilla $^{2}$ \\ Published online: 13 February 2020 \\ (C) Springer Science+Business Media, LLC, part of Springer Nature 2020
}

\begin{abstract}
Introduction This research analyzes the prevalence of sexting and socio-demographic correlates in a sample of 647 adolescents administered a questionnaire at secondary schools in Valencia (Spain).

Methods The questionnaire results indicate that $61 \%$ of respondents reported being involved in at least one case of sexting, with 24,58 , and $18 \%$ reporting having sent a sext, received a sext, and forwarded a sext, respectively.

Results More males and older adolescents reported having received and forwarded sexts than female and younger adolescents. Conclusions Furthermore, time spent using Information and Communications Technology (ICT) devices, use and frequency of use of social media, grade repetition, low academic performance expectations in Math, and a single-parent family situation appear to correlate with an increase in the prevalence of sexting experiences.

Policy Implications Our study also provides results that can support new lines of inquiry into analyzing the relationship between sexting and certain socio-demographic, family situation, and educational variables in relation to adolescents.
\end{abstract}

Keywords Sexting prevalence $\cdot$ Adolescents $\cdot$ ICT $\cdot$ School $\cdot$ Family

Sexting is a form of communication recently adopted by adolescents as a means of exploring and managing sexual intimacy via digital media (Döring, 2014; Parker, Blackburn, Perry, \& Hawks, 2013). It is often considered a normalized form of sexual expression in the context of sexual or romantic relations (Cooper, Quayle, Jonsson, \& Svedin, 2016; Döring, 2014). Sexting also allows many adolescents, particularly those who are otherwise less prepared to do so, to initiate new affective relationships or to fulfill a sexual purpose (Burkett, 2015; Döring, 2014; Lenhart, 2009; Lippman \& Campbell, 2014). In this regard, sexting may be construed as a legitimate form of personal exchange, usually aimed at connecting with, flirting with, or seducing other people.

Electronic supplementary material The online version of this article (https://doi.org/10.1007/s13178-020-00434-0) contains supplementary material, which is available to authorized users.

Cristian Molla-Esparza

Cristian.Molla@uv.es

1 Department of Research Methods and Educational Diagnosis, University of Valencia (UVEG), Av. Blasco Ibáñez 30, 46010 Valencia, Spain

2 Department of Psychobiology and Methodology of Health Science, Autonomous University of Barcelona, UAB, Barcelona, Spain
However, over the past few years, literature on sexting has primarily focused on its associated risks, particularly to the well-being of adolescents (Barrense-Dias, Berchtold, Suris, \& Akre, 2017; Drouin, Ross, \& Tobin, 2015; Ybarra \& Mitchell, 2014). Adolescence is an intense period of biological, physiological, and social transition and of sexual identity development (Burén \& Lunde, 2018). Participating in sexting during this transitional and developmental stage may expose adolescents to undue risks as they may not yet have the maturity to recognize the potential consequences of such sexually charged activities (Gámez-Guadix \& Santisteban, 2018; Houck et al., 2014). One of the main concerns is intentional yet non-consensual distribution of sexting contents (or "sexts"), whose prevalence among youths has been shown to lie between 8.40 and $15.60 \%$ (Madigan, Ly, Rash, Van Ouytsel, \& Temple, 2018). Therefore, at the same time as adolescents are pursuing their own sexual interests, they are also being exposed to various forms of online and offline victimization (Gassó, Klettke, Agustina, \& Montiel, 2019; Kernsmith, Victor, \& Smith-Darden, 2018). Some researchers have found, for example, that adolescents engaging in sexting were more likely to experience dating violence, sexual harassment, and sexual solicitation in general (Gámez-Guadix \& Mateos-Pérez, 2019; Morelli, Bianchi, Baiocco, Pezzuti, \& Chirumbolo, 2016a; Van Ouytsel, Ponnet, \& Walrave, 
2018). Furthermore, a longitudinal bidirectional association has been identified between sexting and the severe online form of victimization known as cyberbullying (Van Ouytsel, $\mathrm{Lu}$, Ponnet, Walrave, \& Temple, 2019). Due to such possible negative consequences of sexting, more empirical research is needed to develop a deeper understanding of this practice and its prevalence.

The phenomenon of sexting has, indeed, triggered a proliferation of studies on its prevalence, although sufficiently precise figures in samples of adolescents are still lacking (Barrense-Dias et al., 2017; Madigan et al., 2018; Ybarra \& Mitchell, 2014). As recent reviews on the subject have indicated, a major reason for high variability in prevalence estimates is the great variety of reference elements in the definition of sexting used in empirical studies (Barrense-Dias et al., 2017). Although there has been sufficient consensus considering sexting as the act of sending sexts, that is, sexually suggestive photos or videos of oneself (Lenhart, 2009; Walker \& Moak, 2010), considerable conceptual and methodological differences exist in the precise definition of sexting used in individual studies. For example, in studies by Mitchell, Finkelhor, Jones, and Wolak (2012) and Crimmins and Seigfried-Spellar (2014), sexting was taken to mean original sexual content sent and received, while Hudson and Fetro (2015) also included the forwarding of such content. Other reference elements used in previous studies include the following: (a) multimedia content formats, such as text messages, images, and videos (Gámez-Guadix, de Santisteban, \& Resett, 2017); (b) recipient types (Branch, HilinskiRosick, Johnson, \& Solano, 2017; Morelli, Bianchi, Baiocco, Pezzuti, \& Chirumbolo, 2016b); (c) types of relationship with the sender or receiver, such as committed, casu$\mathrm{al}$, or spontaneous partner or internet acquaintance (Drouin, Coupe, \& Temple, 2017); (d) consent to sending the content (Morelli et al., 2016a, 2016b); and (e) the frequency of the practice (Lim, Vella, Horyniak, \& Hellard, 2016). In summary, such variability in conceptual elements has been a major obstacle to obtaining precise prevalence estimates in adolescent samples (Klettke, Hallford, \& Mellor, 2014; Madigan et al., 2018). Consequently, a further attempt at assessing the prevalence of sexting in adolescents, bringing together for consideration in one study the varied conceptual references used in previous literature, is justified and can undoubtedly contribute to a clearer and more universal operational definition of sexting (Barrense-Dias et al., 2017).

Studies on sexting in adolescents have also focused on analyzing associated correlates, though results have led to disparate conclusions. Though the majority of studies have considered similar correlates, such as technological device use, social media use, age, and sex (Baumgartner, Sumter, Peter, Valkenburg, \& Livingstone, 2014), few similarities appear in the results. For example, regarding sex, although some studies suggest that males were considerably more likely to practice sexting (Gregg, Somers, Pernice, Hillman, \& Kernsmith, 2018; Patrick, Heywood, Pitts, \& Mitchell, 2015; West et al., 2014), others suggest that, on the contrary, females were more likely to participate in the practice (Reyns, Henson, \& Fisher, 2014; Ybarra \& Mitchell, 2014), or that sex was not a significant correlate (Baumgartner et al., 2014; Benotsch, Snipes, Martin, \& Bull, 2013; Gámez-Guadix \& Mateos-Pérez, 2019; Hinduja \& Patchin, 2010; Lenhart, 2009; Ricketts, Maloney, Marcum, \& Higgins, 2015). Regarding age, while some studies suggest the prevalence of sexting increased considerably with age (Bianchi, Morelli, Baiocco, \& Chirumbolo, 2019; Cox Communications, 2009; Dake, Price, Mazriaz, \& Ward, 2012; Gámez-Guadix \& Mateos-Pérez, 2019; Gregg et al., 2018; Mitchell et al., 2012; Rice et al., 2012, 2018 Vanden Abeele, Campbell, Eggermont, \& Roe, 2014; Wood, Barter, Stanley, Aghtaie, \& Larkins, 2015), ${ }^{1}$ other studies suggest no significant correlation (Benotsch et al., 2013; Gordon-Messer, Bauermeister, Grodzinski, \& Zimmerman, 2013; Morelli et al., 2016b; Ricketts et al., 2015; Woodward, Evans, \& Brooks, 2017). Regarding the use of the internet and technological communication devices, it has generally been found that: adolescents who used the internet more frequently were more likely to practice sexting (Baumgartner, Sumter, Peter, \& Valkenburg, 2012; Baumgartner et al., 2014); the frequency of sending text messages positively correlated with the sending of sexts (Dake et al., 2012; Martínez-Prather \& Vandiver, 2014; Rice et al., 2018; Strassberg, Cann, \& Velarde, 2017; West et al., 2014)²; and internet addiction issues correlated with increased sexting (Ricketts et al., 2015). However, in a study by Bauermeister, Yeagley, Meanley, and Pingel (2014), no significant correlations were identified in this regard.

In general, there is a lack of research on sexting correlates concerning family situation and schooling. Family composition has sometimes been considered, with some studies suggesting that children of single-parent families were more likely to be involved in sexting (Chaudhary et al., 2017; Dake et al., 2012; Vanden Abeele et al., 2014; Woodward et al., 2017), though other studies suggest that family composition was not significantly correlated (Van Ouytsel, Van Gool, Ponnet, \& Walrave, 2014). Campbell and Park (2014) examined family connectivity in relation to adolescent sexting via the social emancipation model, with researchers identifying a negative association between mobile contact with family members and sexting. Indeed, the reception of sexts was found to be less prevalent among adolescents, particularly females, who were involved in more frequent mobile phone communications with their families. However, the work status

\footnotetext{
${ }^{1}$ Wood et al. (2015) reported a greater likelihood of sending sexual images with increased age in all countries where they carried out their study and in both sexes. The only exception being in the country of Cyprus.

${ }^{2}$ West et al. (2014) found that, in males, one of the factors associated with an increased likelihood of sexting was the excessive sending of text messages.
} 
of parents has not previously been researched as a predictor variable in adolescent samples. In adult samples, it has only been studied with descriptive indexes (Houck et al., 2014; Ybarra \& Mitchell, 2014). Schooling has been studied as the relationship between educational level and sexting, but results have been contradictory. Some studies suggest no significant relationship between educational level and sexting (Benotsch et al., 2013; Yeung, Horyniak, Vella, Hellard, \& Lim, 2014). Baumgartner et al. (2012), on the other hand, suggest that adolescents with lower educational levels were more likely to experience moderate online risk situations in general, including the practice of sexting. Other studies indicate significant positive correlations between attained educational levels and sexting (Bauermeister et al., 2014), as well as between educational level and the probability of receiving sexts (Davis, Powell, Gordon, \& Kershaw, 2016). According to Ricketts et al. (2015), a higher average of academic qualifications was associated with increased sexting prevalence.

To summarize, the lack of conclusive data on the most commonly studied socio-demographic correlates of sexting is undoubtedly not only affected by the diversity of conceptual references used in the various studies, as highlighted above, but also by methodological differences, such as in research objectives, data collection strategies, the quality of the measuring instruments, and so on. This all contributes to a lack of clear or similar definitions for the practice of sexting. In addition, there is a notable lack of published research on the role of the family in influencing adolescent sexting, and, consequently, on the extent to which parents' circumstances may influence adolescents' participation in sexting, which is particularly relevant given evidence of the positive influence of the family on decisions that adolescents make regarding their sexual activities (Campbell \& Park, 2014). Empirical evidence on the influence of schooling variables is even more scarce, with a better understanding of the relationship between sexting and education levels needed according to Baumgartner et al. (2012) and Ricketts et al. (2015). In particular, it would be useful to be able to better identify adolescents more likely to participate in risk-associated online practices, including sexting (Baumgartner et al., 2012).

In this context, our research set out to achieve two main goals. The first was to conduct research into the prevalence of sexting practices in secondary school students in Spain, since sexting research has mostly been conducted in the USA, as evidenced by Klettke et al. (2014) in their study on the number and global distribution of sexting studies, and by Madigan et al. (2018) in their recent sexting prevalence meta-analysis. In Spain, sexting research remains particularly scarce, though relevant contributions have been made regarding young Spanish adults by authors such as Gámez-Guadix et al. (2017) and Villacampa (2017). The present study aims to further analyze the prevalence of sexting by differentiating between the following four conceptual references used in previous studies: (a) the experiences involved in sexting, such as sending, receiving, or forwarding; (b) the format of multimedia content transmitted as sexts, such as text message, image, video, audio, or link; (c) the type of protagonist of the sext, such as an acquaintance, student of the same school, or a non-acquaintance; and (d) the transmission channel of the content. The second goal was to study the relationship between sexting experiences and socio-demographic variables, such as sex and age, family composition and work status, school characteristics, such as attendance of a public or charter school, being a student new to the school, the repetition of a grade or expected academic performance, and the use of technological communication devices and social media.

\section{Methodology}

The research design of this study was of cross-sectional survey type, with data collection through a voluntary and anonymous paper questionnaire distributed in school classrooms to a non-random sample of adolescent students.

\section{Participants}

The sample consisted of 647 adolescents ( $52.20 \%$ identifying as male and $47.80 \%$ identifying as female), aged between 12 and 18 years $(M=13.70, D T=1.24)$, from two secondary charter schools and two state schools in the south of the Spanish Province of Valencia. Most participants attended state schools (71.90\%), had not repeated a grade (77\%), and lived with both parents $(90.20 \%)$. They used an average of 2.76 $(S D=1.50)$ technological communication devices, used for a mean of $3 \mathrm{~h}$ on a typical weekday, and engaged with an average of $3.42(S D=3.12)$ social media platforms with a high frequency of use $(M=4.07)$. Additional demographic, family, and educational characteristics are presented in Table 1.

\section{Data Collection}

A questionnaire was designed to achieve the stated objectives of this study, with questions aimed at allowing the researchers to collect data on technological communication device and social media use, socio-demographics, family situation, schooling variables, and sexting experiences. The questionnaire was composed of 23 questions with different answer types: dichotomous, single, or multiple selection choice, Likert scales with four and five linguistic quantifiers, and short open-ended (see Appendix 1).

Use of Technological Communication Devices and Social Media The questionnaire asked the number of technological devices used and their use in hours per day (questions 11 to 13), as well as the number of social media platforms used, 
Table 1 Respondents' socio-demographic, family, and schooling characteristics

\begin{tabular}{|c|c|c|}
\hline \multirow[b]{2}{*}{ Sex } & \multicolumn{2}{|c|}{ Total sample $n=647, \%(n)$} \\
\hline & & \\
\hline Male & 52.20 & (338) \\
\hline Female & 47.80 & (309) \\
\hline \multicolumn{3}{|l|}{ Age (years) } \\
\hline Minimum & 12 & \\
\hline Maximum & 18 & \\
\hline Range & 6 & \\
\hline Mean $(M)$ & 13.70 & \\
\hline Standard deviation $(S D)$ & 1.24 & \\
\hline 12 & 20.70 & (134) \\
\hline 13 & 24.10 & (156) \\
\hline 14 & 27.60 & (178) \\
\hline 15 & 21.50 & (139) \\
\hline$\geq 16$ & 6.10 & $(40)$ \\
\hline \multicolumn{3}{|l|}{ Family situation } \\
\hline Nuclear family & 90.20 & $(581)$ \\
\hline Single-parent family & 9.80 & (63) \\
\hline \multicolumn{3}{|l|}{ No. of siblings } \\
\hline None & 27.40 & (170) \\
\hline One & 57.70 & $(358)$ \\
\hline Two & 12.30 & $(76)$ \\
\hline Three & 1.60 & (10) \\
\hline Four or more & 1 & (6) \\
\hline \multicolumn{3}{|l|}{ Family work status } \\
\hline Neither parent works & 6.70 & (43) \\
\hline At least one parent works & 40.30 & $(259)$ \\
\hline Both work & 52.60 & $(340)$ \\
\hline \multicolumn{3}{|l|}{ School type } \\
\hline State & 71.90 & $(465)$ \\
\hline Charter & 28.10 & (182) \\
\hline \multicolumn{3}{|l|}{ School grade } \\
\hline First grade & 29.80 & (193) \\
\hline Second grade & 26 & (168) \\
\hline Third grade & 23.50 & $(152)$ \\
\hline Fourth grade & 20.70 & (134) \\
\hline \multicolumn{3}{|l|}{ School seniority } \\
\hline Not in the first year at the school & 76.70 & (494) \\
\hline In the first year at the school & 23.30 & $(150)$ \\
\hline \multicolumn{3}{|l|}{ Year repeated } \\
\hline No & 77 & (498) \\
\hline Yes & 23 & (149) \\
\hline \multicolumn{3}{|l|}{ Expected result in Math } \\
\hline Fail & 16.70 & (108) \\
\hline Pass (Pass or Good) & 50.10 & (324) \\
\hline Good grade (Merit or Distinction) & 33.20 & $(215)$ \\
\hline \multicolumn{3}{|l|}{ Expected result in Spanish } \\
\hline Fail & 7.10 & (46) \\
\hline Pass (pass or good) & 58 & $(375)$ \\
\hline Good grade (merit or distinction) & 34.90 & (226) \\
\hline
\end{tabular}

their frequency of use, on a 5-point Likert scale, and the format of multimedia content most frequently exchanged on such platforms (questions 14 to 17). The five-point scale was subsequently dichotomized as follows: low usage frequency, 1 to 3 , versus high usage frequency, 4 or 5 . The formats of multimedia non-sexual content considered were text messages, images/photos, videos, audio messages, and internet links.

Socio-Demographic, Family and Educational Variables The participants indicated their sex, age, family situation, and the work status of their parents (questions 1, 3, 5, and 6). Regarding their family situation, they were asked whether they lived with both parents or only one, the number of siblings they had, and the parents' work status, that is whether both were working, only one was working, or both were not working. Regarding schooling, respondents were asked whether their school was a state or charter school, which grade they were in, whether it was their first year at the school, and whether they had repeated a grade (questions 2, 4, 7, and 8). Regarding academic performance, respondents indicated whether they expected to fail, pass, or get a good mark in the subjects of Math and Spanish (questions 9 and 10).

Sexting Experiences Sexting questions were developed through two processes: (a) a conceptual and semantic adaptation of surveys used in previous research on sexting (Bauermeister et al., 2014; Baumgartner et al., 2012; Benotsch et al., 2013; Mitchell et al., 2012; Rice et al., 2014; Temple et al., 2012), and (b) a discussion group conducted with adolescents. This strategy was proposed in order to adapt the questionnaire to the participants. The discussion group was formed by ten adolescents with the same profile of the respondents, that is students in their last grade of primary school and students in secondary education, selected by convenience, and the discussion lasted for 70 minutes.

In the questionnaire, sexting experiences were first recorded by three questions, with a 5-point Likert response, assessing lifetime experience of sending, receiving, and forwarding of provocative or erotic content by mobile or internet (question 18). Secondly, the format of the multimedia content sent or received as sexts was indicated (question 19), as well as the sex of the protagonist of the sexts (question 20) and the transmission channel (question 21). Furthermore, it was asked whether or not the content of the sexts was intended to harm their protagonists (question 22). Finally, respondents were asked whether they thought any educational measures should be implemented in schools to inform them of sexting practices (question 23).

\section{Procedure}

The administrations of the schools were contacted by telephone in order to arrange meetings and explain the study's goals. In each case, the school principal, together with the school board members, decided whether or not the school should participate. Parents were informed of the study and of their right to refuse the participation of their children; $1.22 \%(n=8)$ rejected it.

The questionnaire was administered to the participating adolescents in their usual classrooms, during regular class hours. The questionnaire included an introductory section 
explaining the aims of the study and informing the participants of its voluntary, anonymous, and confidential nature. The participants also received verbal instructions from the researchers. The procedure respected the fundamental the principles of the participants' right to be informed, of the protection of their personal data, of the guarantee of the confidentiality of such data, of non-discrimination, and of the freedom for the participants to abandon the study at any time during the data collection. Participants did not receive any compensation.

\section{Data Analysis}

We computed descriptive statistics regarding the socio-demographic, family situation, and educational characteristics associated with the adolescents. Sexting prevalence was assessed in the overall sample, as well as by sex. Chi-squared statistics were used to assess dichotomous data and effect sizes were calculated as the difference of proportions $(95 \% \mathrm{CI})$.

Questionnaire response options corresponding to the experiences of sending, receiving, and forwarding sexts were dichotomized and three binary logistic regression models were constructed with the maximum likelihood adjustment method in order to analyze the effect of potential predictor variables (Hair, Black, Babin, \& Anderson, 2010). The three models included the following predictor variables: sex, age, family situation, parents' work status, school type, being new to the school, repetition of a grade, expected academic performance in Math and Spanish, the number of technological communication devices used and their frequency of use, and the number of social media platforms used and their frequency of use. Since the three sexting experiences analyzed, that is sending, receiving, and forwarding, have a strong substantive association, each of the three regression models excluded the other two sexting experiences as covariates. To guarantee the statistical validity of the models, the assumptions of linearity of the covariates were checked against the logit of responses, error independence, and the absence of overdispersion, of collinearity between covariates and of atypical and influential values.

An analysis of missing values gave percentages not exceeding 5\% in any of the three response variables (i.e. sending, receiving, or forwarding sexts). The results of a Missing Completely at Random (MCAR, Little \& Rubin, 2002) test questioned the randomness of the distribution of the missing responses. Consequently, simple imputations were made according to the metrics of these variables, as well as posterior comparisons between imputed and non-imputed pairs of variables, which did not reveal significant differences in any of them. The modeling of the regression equations was performed with $97.50 \%$ of the total sample. All analysis was performed using SPSS version 25.0.

\section{Results}

\section{Prevalence and Characteristics of Sexting Experiences}

Table 2 shows prevalence results for sending, receiving, and forwarding sexts. Of the sample, $60.59 \%$ (95\% CI 56.82, $64.35 \%$ ) had been involved in at least one of the sexting experiences. Of the adolescents, $24.27 \%$ (95\% CI 20.96, $27.57 \%$ ) had sent sexts one or more times, $57.96 \%$ (95\% CI $54.16,61.76 \%)$ had received sexts, and $17.93 \%$ (95\% CI $14.97,20.88 \%$ ) had forwarded sexts.

Sending and forwarding experiences were reported as sporadic or occasional ("at least once" or "occasionally"), while receiving sexts was reported to have occurred at higher frequencies ("often" or "very often") (Table 2). Sending sexts correlated with receiving sexts $(p=.00)(d=.39 ; 95 \% \mathrm{CI}$ $.32, .46)$ and forwarding sexts $(p=.00)(d=.22 ; 95 \%$ CI .14, $.30)$, and receiving sext correlated with forwarding sexts $(p=.00)(d=.26 ; 95 \%$ CI .21, .31).

As shown in Table 3, although the type of general nonsexual content that adolescents most sent or received via technological devices were text messages $(94.28 \%$; $95 \%$ CI 92.49 , $96.07 \%$ ), the content most sent or received as sexts were images $(47.60 \%$; 95\% CI 43.76, 51.45\%) and videos (23.18\%; 95\% CI 19.93, 26.44\%). Among those who had sent or received sexts, males exchanged more erotic videos than females $(65.20$ vs. $34.80 \%)(p=.00)(d=-.15 ; 95 \%$ CI -.25 , $-.05)$, as well as more internet links than females (67.80 vs. $32.20 \%)(p=.04)(d=-.15 ; 95 \% \mathrm{CI}-.28,-.01)$.

As shown in Table 4, received sexts mainly featured protagonists that were known adolescents $(42.50 \%$; $95 \% \mathrm{CI}$ $38.69,46.31 \%)(18.90 \%$ males and $23.60 \%$ females $)$. Also protagonists in sexts, although to a lesser extent, were unknown adolescents $(23.90 \%$; $95 \%$ CI 20.65, 27.19\%) (8\% males and $15.90 \%$ females), students at the same school (23.30\%; 95\% CI 20.10, 26.60\%) $(11.10 \%$ males and $12.20 \%$ females), unknown adults $(11.70 \%$; $95 \%$ CI 9.24, $14.18 \%)$, and known adults (3.10\%; 95\% CI 1.76, 4.42\%). The results evidence that males received more sexts with female protagonists than male protagonists, while females received more sexts with male protagonists than female protagonists.

Regarding transmission channels, sexts were mainly received via one-to-one channels $(63.20 \%$; $95 \%$ CI 58.32 , $68.08 \%$ ). Also, $43.40 \%$ (95\% CI 38.22, 48.54\%) had received sexts exclusively via one-to-one channels, $33.24 \%$ (95\% CI $28.34,38.14 \%$ ) exclusively via group channels, and $23.38 \%$ (95\% CI 18.98, 27.78\%) via both types of channel. As shown in Table 5, males who received sexts exclusively via one-toone channels mainly featured female adolescent protagonists they knew $(54.90 \%)$, followed by female students of the same school (22\%), while males who received sexts exclusively via group channels mainly featured protagonists who were male 
Table 2 Prevalence of sending, receiving, and forwarding sexts among adolescents

\begin{tabular}{|c|c|c|c|c|c|}
\hline & \multicolumn{3}{|c|}{$\begin{array}{l}\text { Total sample } \\
(n=647)\end{array}$} & \multirow{2}{*}{$\begin{array}{l}\text { Males } \\
\%,(n)\end{array}$} & \multirow{2}{*}{$\begin{array}{l}\text { Females } \\
\%,(n)\end{array}$} \\
\hline & $\%$ & $(95 \% \mathrm{CI})$ & $(n)$ & & \\
\hline \multicolumn{6}{|l|}{ Sending sexts } \\
\hline Never & 74.50 & $(71.14,77.86)$ & $(482)$ & $51.70,(249)$ & $48.30,(233)$ \\
\hline Had sent sexts & 24.27 & $(20.96,27.57)$ & (157) & $52.90,(83)$ & $47.10,(74)$ \\
\hline At least once & 14.84 & $(12.10,17.58)$ & (96) & $46.90,(45)$ & $53.10,(51)$ \\
\hline Occasionally & 7.26 & $(5.26,9.26)$ & (47) & $57.40,(27)$ & $42.60,(20)$ \\
\hline Often & .93 & $(.19,1.67)$ & $(6)$ & $100,(6)$ & $0,(0)$ \\
\hline \multirow[t]{3}{*}{ Very often } & 1.24 & $(.38,2.09)$ & (8) & $62.50,(5)$ & $37.50,(3)$ \\
\hline & & & & $52.90,(83)$ & $47.10,(74)$ \\
\hline & & & & \multicolumn{2}{|c|}{$\begin{array}{l}\text { Chi-square test: }(p \text { value }=.80) \\
\text { Effect size }(d)-.01 ;(-.10, .08)\end{array}$} \\
\hline \multicolumn{6}{|l|}{ Receiving sexts } \\
\hline Never & 42.04 & $(38.24,45.84)$ & (272) & $47.80,(130)$ & $52.20,(142)$ \\
\hline Had received sexts & 57.96 & $(54.16,61.76)$ & $(375)$ & $54.92,(201)$ & $45.08,(165)$ \\
\hline At least once & 25.81 & $(22.44,29.18)$ & (167) & $47.50,(75)$ & $52.50,(83)$ \\
\hline Occasionally & 19.47 & $(16.42,22.53)$ & (126) & $57.90,(73)$ & $42.10,(53)$ \\
\hline Often & 9.89 & $(7.59,12.19)$ & (64) & $68.80,(44)$ & $31.30,(20)$ \\
\hline \multirow[t]{3}{*}{ Very often } & 2.78 & $(1.51,4.05)$ & (18) & $50,(9)$ & $50,(9)$ \\
\hline & & & & $54.92,(201)$ & $45.08,(165)$ \\
\hline & & & & \multicolumn{2}{|c|}{$\begin{array}{l}\text { Chi-square test: }(p \text { value }=.05) \\
\text { Effect size }(d)-.08 ;(-.15, .00)\end{array}$} \\
\hline \multicolumn{6}{|l|}{ Forwarding sexts } \\
\hline Never & 82.07 & $(79.12,85.03)$ & (531) & $48.70,(253)$ & $51.30,(267)$ \\
\hline Had forwarded sexts & 17.93 & $(14.97,20.88)$ & (116) & $65.52,(76)$ & $54.92,(40)$ \\
\hline At least once & 11.44 & $(8.98,13.89)$ & (74) & $67.60,(50)$ & $32.40,(24)$ \\
\hline Occasionally & 4.79 & $(3.15,6.44)$ & $(31)$ & $58.10,(18)$ & $41.90,(13)$ \\
\hline Often & .77 & $(.10,1.45)$ & (5) & $80,(4)$ & $20,(1)$ \\
\hline \multirow[t]{3}{*}{ Very often } & .93 & $(.19,1.67)$ & (6) & $66.70,(4)$ & $33.30,(2)$ \\
\hline & & & & $65.52,(76)$ & $54.92,(40)$ \\
\hline & & & & \multicolumn{2}{|c|}{$\begin{array}{l}\text { Chi-square test: }(p \text { value }=.00) \\
\text { Effect size }(d)-.16 ;(-.26,-.07)\end{array}$} \\
\hline \multirow[t]{2}{*}{ Had been involved any such experiences } & 60.59 & $(56.82,64.35)$ & $(392)$ & $55.40,(217)$ & $44.60,(175)$ \\
\hline & & & & \multicolumn{2}{|c|}{$\begin{array}{l}\text { Chi-square test: }(p \text { value }=.03) \\
\text { Effect size }(d)-.09 ;(-.17,-.01)\end{array}$} \\
\hline
\end{tabular}

Note: $p$ value associated with Chi-square test

adolescents from their own school (26.90\%), followed by male adolescents they knew $(25.60 \%)$. Females who received sexts exclusively via one-to-one channels mainly featured protagonists who were known male adolescents $(59 \%)$. However, females who received sexts exclusively via group channels featured protagonists who were known female adolescents $(28.60 \%)$. When sexts were received exclusively via one-to-one channels, the results were similar to when the transmission channel was indistinguishable in that the adolescents received more sexts with adolescent protagonists of the opposite sex. The same was not true with sexts received exclusively via group channels.
When asked whether the contents of sexts were intended to harm their protagonists, $58.93 \%$ (95\% CI 54.29, 63.58\%) of participants responded "no," while $41.07 \%$ (95\% CI 36.42, $45.71 \%$ ) of participants responded "yes." When considering both the total sample and the subsample of adolescents involved in any of the sexting experiences, more females than males reported that sexts were intended to harm the protagonist ( $p=.00$ and $p=.02$, respectively) $(d=.14 ; 95 \%$ CI .05 , .24 and $d=.12 ; 95 \%$ CI .02, .22, respectively).

Regarding the potential implementation educational measures in schools in order to inform students on the phenomenon of sexting, $73.78 \%$ (95\% CI 70.35, 77.20\%) of the sample 
Table 3 Sexts exchanged by males and females

\begin{tabular}{|c|c|c|c|c|c|c|c|c|c|}
\hline \multirow[t]{2}{*}{ Media content } & \multicolumn{3}{|c|}{$\begin{array}{l}\text { General media content } \\
\text { (no sexts) }\end{array}$} & \multicolumn{3}{|c|}{$\begin{array}{l}\text { Sexting media content } \\
\text { (sexts) }\end{array}$} & \multicolumn{2}{|c|}{ Sexts exchanged by } & \multirow{2}{*}{$\begin{array}{l}\text { Chi-square test; } \\
\text { Effect size \& 95\% CI }\end{array}$} \\
\hline & $\%$ & $(95 \% \mathrm{CI})$ & $(n)$ & $\%$ & $(95 \% \mathrm{CI})$ & $(n)$ & $\begin{array}{l}\text { Males } \\
\%,(n)\end{array}$ & $\begin{array}{l}\text { Females } \\
\%,(n)\end{array}$ & \\
\hline Texts & 94.28 & $(92.49,96.07)$ & 610 & 17.47 & $(14.54,20.39)$ & 113 & $49.10(53)$ & $50.90(55)$ & $\begin{array}{l}p=.12 \\
d=.09(-.02, .20)\end{array}$ \\
\hline Images & 92.27 & $(90.21,94.33)$ & 597 & 47.60 & $(43.76,51.45)$ & 308 & $56.30(165)$ & $43.70(176)$ & $\begin{array}{l}p=.56 \\
d=-.03,(-.15, .08)\end{array}$ \\
\hline Videos & 90.68 & $(88.44,92.93)$ & 584 & 23.18 & $(19.93,26.44)$ & 150 & $65.20(92)$ & $34.80(49)$ & $\begin{array}{l}p=.00 ; \\
d=-.15,(-.25,-.05)\end{array}$ \\
\hline Audios & 90.57 & $(88.32,92.82)$ & 586 & 6.49 & $(4.59,8.39)$ & 42 & $45(18)$ & $55(22)$ & $\begin{array}{l}p=.16 \\
d=.12,(-.05, .28)\end{array}$ \\
\hline Links & 83.85 & $(81.01,86.69)$ & 540 & 9.74 & $(7.45,12.02)$ & 63 & $67.80(40)$ & $32.20(19)$ & $\begin{array}{l}p=.04 \\
d=-.15,(-.28,-.01)\end{array}$ \\
\hline
\end{tabular}

Note: $p$ value associated with Chi-square test

$E S$ effect size and $95 \% \mathrm{CI}$

considered such measures necessary, while $26.22 \%$ (95\% CI $22.80,29.65 \%$ ) of the sample considered them unnecessary. Both in the total sample and in the subsample of those involved in any of the sexting experiences, more females than males felt it necessary to implement such educational measures $(p=.00$ and $p=.00$, respectively) $(d=-.18 ; 95 \% \mathrm{CI}$ $-.27,-.10$ and $d=-.19 ; 95 \%$ CI $-.29,-.09$, respectively).

\section{Analysis of Socio-Demographic, Family Situation and Educational Correlates of Sexting Experiences}

Table 6 indicates the results of the binary logistic regression model for sending sexts, including exclusively the values of predictor variables whose adjusted odds ratios (ORadj) were statistically significant. The data reveals a significant global adjustment $\left(\chi^{2}(16)=52.17 ; p=.00\right)$, with the covariates reducing the divergence of the null model by $12.10 \%\left(R^{2}\right.$ Nagelkerke $=.12$ ). The Hosmer and Lemeshow test indicates a good model fit (.21). Three covariates appeared to have a statistically significant effect on sending sexts: repetition of a grade $(p=.04)$, the number of social media platforms used $(p=.00)$, and the frequency of their use $(p=.03)$.

The sending of sexts correlated significantly with the number of social media platforms networks used (OR 1.18, 95\% CI 1.07, 1.30). In addition, adolescents who used social media more frequently were 2.12 times more likely to have sent a sext $(95 \%$ CI 1.09, 4.13). Furthermore, those who had repeated a grade were 1.70 times $(95 \%$ CI $1.02,2.82)$ more likely to have sent a sext than those who had never repeated a grade.

Results for the logistic regression analyzes for receiving sexts (Table 6) show that the final model contributes considerably to improving the null model fit $\left(\chi^{2}(7)=139.56\right.$; $p=.000)$. The Hosmer and Lemeshow test indicates a good model fit (.57). According to the Nagelkerke coefficient,
$27.20 \%$ of the dependent variable (receiving sexts) is indicated by the covariates: $\operatorname{sex}(p=.01)$, age $(p=.00)$, family situation $(p=.01)$, number of social media platforms used $(p=.00)$, their frequency of use $(p=.00)$, and technological communication device use time $(p=.017)$.

The final model shows that receiving sexts correlated significantly with sex, with more males involved in this experience (OR .58, 95\% CI .40, .85). Age also turned out to be a clearly significant predictor variable, indicating that older adolescents in general were more likely to have received sexts (OR 1.50, 95\% CI 1.22, 1.83). Regarding family situation, adolescents who reported living in a single-parent family were 2.82 times more likely to have received sexts (95\% CI 1.37 , 5.83). Regarding the use of social media, adolescents who reported engaging with a greater number of social media platforms (OR $1.24,95 \%$ CI $1.12,1.38)$ were more likely to receive sexts. Likewise, the frequency of use of social media positively correlated with receiving sexts (OR $2.30,95 \% \mathrm{CI}$ $1.38,3.85)$. Regarding the use of technological communication devices, the more time they reported using such devices, the more likely adolescents were to have received sexts (OR $1.09,95 \%$ CI $1.02,1.17)$.

The third regression model concerning forwarding sexts shows that the proposed model contributes significantly to reducing the divergence of the null model $\left(\chi^{2}(16)=60.58\right.$; $p=.00$ ). The Hosmer and Lemeshow test indicates an adequate model fit (.632). The set of included variables reduced the divergence in relation to the null model by $15.40 \%$. Four covariates appeared to have a statistically significant effect on forwarding sexts: sex $(p=.00)$, age $(p=.01)$, respondents' expectations for academic results in Math $(p=.04)$, and the number of social media platforms used $(p=.02)$.

The results indicate that being male correlated significantly with forwarding sexts (OR .44, 95\% CI .27, .71). Older 
Table 4 Protagonists of sexts received by males and females

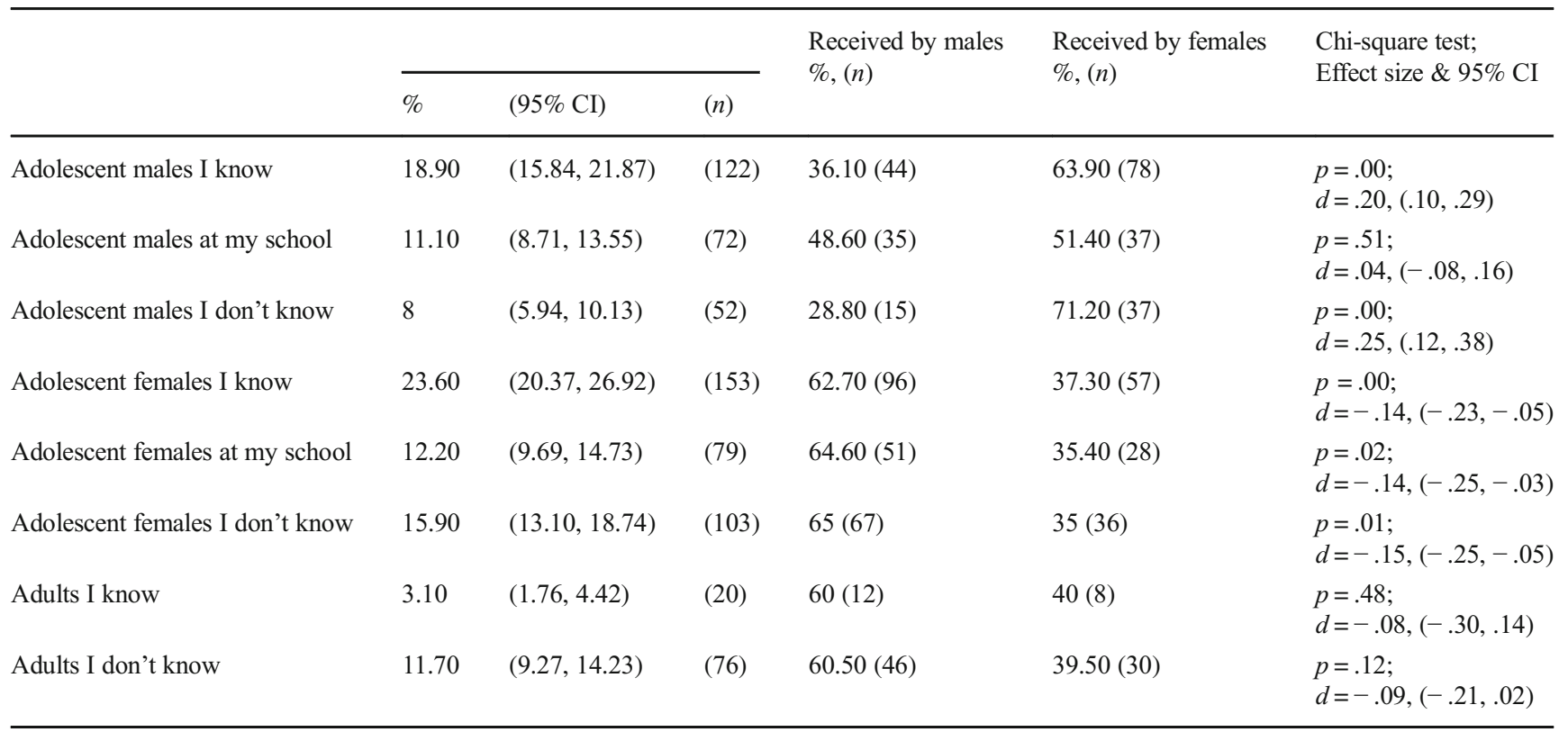

Note: $p$ value associated with Chi-square test

adolescents were 1.37 times (OR 1.37, 95\% CI 1.10, 1.70) more likely to have reported forwarding sexts. Furthermore, adolescents with lower expectations for their academic results in Math were more likely to have forwarded sexts (OR .59, $95 \%$ CI .36, .97). Finally, a greater number of social media platforms used significantly increased the likelihood of having forwarded sexts (OR 1.13, 95\% CI 1.02, 1.26).

\section{Discussion}

This study examines the prevalence of the phenomenon of sexting, and identifies several associated socio-demographic, family situation, and educational correlates. It is one of only a few studies that presents and analyzes disaggregated sexting prevalence data in relation to various basic reference elements in the definition of sexting. The study considers three main sexting experiences, sending, receiving, and forwarding, five multimedia formats (texts, images, videos, audio messages, and links), the profile of the protagonists featuring in the sexts, and the content transmission channel. By including a broader range of sexting's defining elements, we have been able to characterize sexting participants better than previous studies that have only partially studied or totally ignored such elements.

Our results suggest that sexting is a common practice among Spanish adolescents. In our sample of adolescents from 12 to 18 years of age, around 24\% admitted to having sent sexts, $58 \%$ to having received sexts, and $18 \%$ to having forwarded sexts. Such results are consistent with estimates of sexting prevalences yielded by research conducted across five
European countries (see Stanley et al., 2018, and Wood et al., 2015). Our prevalence for sending sexts was, however, higher than that reported by other recent studies carried out in Spain (Gámez-Guadix \& Mateos-Pérez, 2019; Gámez-Guadix \& Santisteban, 2018; Gámez-Guadix et al., 2017), although comparisons should be made with caution, considering the considerable conceptual and methodological differences between studies, as discussed in the introduction to this study.

The predominant format of sexts reported by our sample of adolescents were images, in agreement with results from Villacampa (2017) and Hudson and Marshall (2016), but not from Gámez-Guadix et al. (2017) and the National Campaign to Prevent Teen and Unplanned Pregnancy (NCPTUP, 2008), which reported a more common exchange of sexual content in the form of written text than in the form of photos, images, or videos. It is important to note that the exchange of sexual pictures may require a higher degree of exposure and of trust between the sender and receiver compared to the exchange of sexual text messages. In this regard, our study went a step further in considering not only the text messages, images, and videos commonly considered in previous studies, but also audio recordings of a sexual nature, which can very easily be used by adolescents to stimulate or satisfy their own or others' sexual pleasures. The present study also expanded on previous research in an important way by differentiating between the protagonists featured in the sexts. As protagonists of the sexts, our respondents mostly reported known adolescents, more than half of whom females, or students from their own school. This confirms the results of Villacampa (2017), which reported $78 \%$ of sexts having protagonists that were minors. In relation to the transmission channel used, we found that sexts 
Table 5 Protagonists of sexts received by males and females via one-to-one or group channels

\begin{tabular}{|c|c|c|c|c|c|c|}
\hline & \multicolumn{3}{|c|}{ Received via one-to-one channel } & \multicolumn{3}{|c|}{ Received via group channel } \\
\hline & $\begin{array}{l}\text { Males } \\
(n), \%\end{array}$ & $\begin{array}{l}\text { Females } \\
(n), \%\end{array}$ & $\begin{array}{l}\text { Differences by sex } \\
\text { (Chi-square test \& ES) }\end{array}$ & $\begin{array}{l}\text { Males } \\
(n), \%\end{array}$ & $\begin{array}{l}\text { Females } \\
(n), \%\end{array}$ & $\begin{array}{l}\text { Differences by sex } \\
\text { (Chi-square test \& ES) }\end{array}$ \\
\hline \multirow{3}{*}{$\begin{array}{l}\text { Males I know } \\
\% \text { within this category } \\
\% \text { within sex }\end{array}$} & (13) & $(46)$ & $p=.00$ & (20) & (11) & $p=.24$ \\
\hline & $22 \%$ & $78 \%$ & $d=.49,(.35, .62)$ & $64.50 \%$ & $35.50 \%$ & $d=-.12,(-.31, .07)$ \\
\hline & $14.30 \%$ & $59 \%$ & & $25.60 \%$ & $7.50 \%$ & \\
\hline \multirow{3}{*}{$\begin{array}{l}\text { Males at my school } \\
\% \text { within this category } \\
\% \text { within sex }\end{array}$} & (7) & (16) & $p=.02$ & $(21)$ & $(15)$ & $p=.67$ \\
\hline & $30.40 \%$ & $69.60 \%$ & $d=.27,(.07, .48)$ & $58.30 \%$ & $41.70 \%$ & $d=-.04,(-.23, .15)$ \\
\hline & $7.70 \%$ & $20.50 \%$ & & $26.90 \%$ & $23.80 \%$ & \\
\hline \multirow{3}{*}{$\begin{array}{l}\text { Males I don't know } \\
\% \text { within this category } \\
\% \text { within sex }\end{array}$} & (2) & (11) & $p=.00$ & (4) & (12) & $p=.01$ \\
\hline & $15.40 \%$ & $84.60 \%$ & $d=.42,(.21, .63)$ & $25 \%$ & $75 \%$ & $d=.34,(.11, .57)$ \\
\hline & $2.20 \%$ & $14.10 \%$ & & $5.10 \%$ & $19 \%$ & \\
\hline \multirow{3}{*}{$\begin{array}{l}\text { Females I know } \\
\% \text { within this category } \\
\% \text { within sex }\end{array}$} & $(50)$ & (23) & $p=.00$ & (19) & (18) & $p=.57$ \\
\hline & $68.50 \%$ & $31.50 \%$ & $d=-.26,(-.40,-.11)$ & $51.40 \%$ & $48.60 \%$ & $d=.05,(-.13, .24)$ \\
\hline & $54.90 \%$ & $29.50 \%$ & & $24.40 \%$ & $28.60 \%$ & \\
\hline \multirow{3}{*}{$\begin{array}{l}\text { Females at my school } \\
\% \text { within this category } \\
\% \text { within sex }\end{array}$} & (20) & (13) & $p=.39$ & (14) & (7) & $p=.26$ \\
\hline & $60.60 \%$ & $39.40 \%$ & $d=-.08,(-.27, .10)$ & $66.70 \%$ & $33.30 \%$ & $d=-.13,(-.35, .09)$ \\
\hline & $22 \%$ & $16.70 \%$ & & $17.90 \%$ & $11.10 \%$ & \\
\hline \multirow{3}{*}{$\begin{array}{l}\text { Females I don't know } \\
\% \text { within this category } \\
\% \text { within sex }\end{array}$} & (17) & (8) & $p=.12$ & (18) & $(15)$ & $p=.92$ \\
\hline & $68 \%$ & $32 \%$ & $d=-.17,(-.37, .03)$ & $54.50 \%$ & $45.50 \%$ & $d=.01,(-.18, .20)$ \\
\hline & $18.70 \%$ & $10.30 \%$ & & $23.10 \%$ & $23.80 \%$ & \\
\hline \multirow{3}{*}{$\begin{array}{l}\text { Adults I know } \\
\% \text { within this category } \\
\% \text { within sex }\end{array}$} & $(0)$ & (3) & $p=\mathrm{n} / \mathrm{a}$ & (8) & $(0)$ & $p=\mathrm{n} / \mathrm{a}$ \\
\hline & $0 \%$ & $100 \%$ & $d=\mathrm{n} / \mathrm{a}$ & $100 \%$ & $0 \%$ & $d=\mathrm{n} / \mathrm{a}$ \\
\hline & $0 \%$ & $3.80 \%$ & & $10.30 \%$ & $0 \%$ & \\
\hline \multirow{3}{*}{$\begin{array}{l}\text { Adults I don't know } \\
\% \text { within this category } \\
\% \text { within sex }\end{array}$} & (14) & (4) $22.20 \%$ & $p=.03$ & (14) & (16) & $p=.28$ \\
\hline & $77.80 \%$ & $5.10 \%$ & $d=-.24,(-.48,-.06)$ & $46.70 \%$ & $53.30 \%$ & $d=.11,(-.09, .31)$ \\
\hline & $15.40 \%$ & & & $17.90 \%$ & $25.40 \%$ & \\
\hline
\end{tabular}

Note: $p$ value associated with Chi-square test

$E S$ effect size and $95 \%$ CI, $n / a$ not applicable

received by male and female adolescents through one-to-one channels had, above all, protagonists of the opposite sex respectively, while sexts received by male and female adolescents through group channels had, predominantly, protagonists of the same sex respectively. This finding suggests that the exchange sexual content through groups is far from being a consensual and exclusive sexual practice between a sender and a receiver. This is a particularly sensitive issue since, as suggested by Lloria (2013), the dissemination of intimate content without the consent of the protagonist beyond the one-toone realm may have considerable psychological, physiological, sexual, academic, and/or social consequences, even more so when framed by a public or threatening context. Another relevant result of our study is that involvement in any of the experiences of sending, receiving, or forwarding sexts seems to correlate with the likelihood of being involved in the other experiences. This confirms the previous results of Rice et al. $(2014,2018)$ regarding the experiences of sending and receiving sexts.

This study also explores sexting's associations with sociodemographic, family situation, and schooling correlates, and the use of technological communication devices and social media platforms. Regarding socio-demographic correlates, our study found that adolescent males receive and forward more sexts than adolescent females. This is in agreement with various previous studies reporting that adolescent males receive more sexts than females (Gordon-Messer et al., 2013; Hinduja \& Patchin, 2010; Morelli et al., 2016b; Strassberg, McKinnon, Sustaíta, \& Rullo, 2013). However, our data is not in agreement with the studies of Dake et al. (2012), Lenhart (2009), NCPTUP (2008), Rice et al. (2012), and Temple et al. (2012), which reported no significant sex differences. One possible explanation for this finding is that females experienced more pressure to send sexts than boys (Drouin \& Tobin, 2014; Lippman \& Campbell, 2014; Wood et al., 2015; Burén \& Lunde, 2018). The decision to engage in sexting may have been influenced by how their immediate environment perceives this practice, in addition to other online and offline sexual risk-associated behaviors. Indeed, the influence of peer groups on sharing sexual content on the internet has been proven in various studies (Houck et al., 2014; Van Ouytsel, Ponnet, Walrave, \& d'Haenens, 2017). Regarding age, our study suggests that older adolescents are more likely to have received and forwarded sexts, in agreement with previous studies (Cox Communications, 2009; Dake et al., 2012; Lenhart, 2009; Mitchell et al., 2012; Rice et al., 2012; Rice et al., 2014; Rice et al., 2018; Strassberg et al., 2013). This may be the result of the combination of the possibilities 
Table 6 Summary of binary logistic regression models predicting sexting experiences among adolescents

\begin{tabular}{|c|c|c|c|}
\hline & $\mathrm{OR}_{\text {adj }}(95 \% \mathrm{CI})$ & $\left(\mathrm{OR}_{\mathrm{adj}}-1\right) \times 100$ & $p$ value \\
\hline \multicolumn{3}{|l|}{ Model 1: sending sexts } & $\chi^{2}=52.17^{* * * ;} ; R^{2}=.121$ \\
\hline Grade repetition (vs. repeated a grade) & $1.70(1.02,2.82)$ & $69.38 \%(2,181.50 \%)$ & .042 \\
\hline Number of social media platforms & $1.18(1.07,1.30)$ & $18.06 \%(7,30 \%)$ & .001 \\
\hline Social media use frequency (vs. daily use) & $2.12(1.09,4.13)$ & $112.34 \%(9.09,312.90 \%)$ & .027 \\
\hline Constant & $B=-4.88 ;(S E=1.42)$ & & .001 \\
\hline \multicolumn{3}{|l|}{ Model 2: receiving sexts } & $\chi^{2}=139.56^{* * * ;}, R^{2}=.272$ \\
\hline Sex (vs. females) & $.58(.40, .85)$ & $-41.70 \%(-60,-15 \%)$ & .005 \\
\hline Age & $1.50(1.22,1.83)$ & $49.60 \%(22.30,83 \%)$ & .000 \\
\hline Family situation (vs. single-parent) & $2.82(1.37,5.83)$ & $182.20 \%(36.60,482.70 \%)$ & .005 \\
\hline Number of social media platforms & $1.24(1.12,1.38)$ & $24.30 \%(12,38 \%)$ & .000 \\
\hline Social media use frequency (vs. daily use) & $2.30(1.38,3.85)$ & $130.30 \%(37.90,284.70 \%)$ & .001 \\
\hline Device use time & $1.09(1.02,1.17)$ & $9.20 \%(1.60,17.40 \%)$ & .017 \\
\hline Constant & $B=-6.51(S E=1.44)$ & & .000 \\
\hline \multicolumn{3}{|l|}{ Model 3: forwarding sexts } & $\chi^{2}=60.58 * * * ; R^{2}=.154$ \\
\hline Sex (vs. females) & $.44(.27, .71)$ & $-56.10 \%(-72.70,-29.50 \%)$ & .001 \\
\hline Age & $1.37(1.10,1.70)$ & $36.50 \%(9.50,70 \%)$ & .006 \\
\hline Expected result in Math (vs. good marks) & $.59(.36, .97)$ & $-40.90 \%(-63.90,-3.20 \%)$ & .037 \\
\hline Number of social media platforms & $1.13(1.02,1.26)$ & $13.10 \%(1.70,25.0 \%)$ & .023 \\
\hline Constant & $B=-6.81(S E=1.59)$ & & .000 \\
\hline
\end{tabular}

Note 1: Logistic regression adjusted odds ratio $\left(\mathrm{OR}_{\mathrm{adj}}\right), 95 \%$ confidence intervals $(95 \% \mathrm{CI})$ and $p$ values $(p)$. $\left(\mathrm{OR}_{\mathrm{adj}}-1\right) \times 100$ indicates the effect of covariables on sexting practices expressed as a percentage change

Note 2: The three binary logistic regression models included the following complete list (Entry) of covariates: sex; age; family situation; family work status; school type; school seniority; grade repeated; expected result in Math; expected result in Spanish; number of devices used; time using devices; number of social media platforms used and frequency of social media use.

$\chi^{2}$ Chi-square value, $R^{2}$ Nagelkerke R squared, $S E$, standard error

$* p<.05 ; * * p<.01 ; * * * p<.001$

offered by ICT use and age-typical sexual needs, for example, the growing need to learn about one's own body and reproductive physiology, to self-explore and to self-stimulate in order to satisfy one's growing sexual desires, and to initiate one's first sexual relationships. Such needs may be satisfied via ICT, which can provide a wealth of information on topics of sexuality, offer a non-physical space for interaction, and play an important role in the development and sexual satisfaction of young people (Bianchi, Morelli, Baiocco, \& Chirumbolo, 2017; Bianchi et al., 2019).

Regarding technological means, our study differentiates between the use of technological communication devices and social media platforms. It indicates that using a greater number of devices was not associated with sexting, though the frequency of their use did correlate positively with having received sexts. Increased number and frequency of use of social media platforms also correlated with higher rates of having sent, received, and forwarded sexts. This is a particularly relevant result given that a number of studies have found a relationship between an adolescent's degree of exposure to the internet and being a victim of both online and offline harassment (Englander, 2015; Choi, Van Ouytsel, \& Temple,
2016; Wolak, Finkelhor, Walsh, \& Treitman, 2018), including blackmail, pressure, and coercion.

As highlighted previously in this article, few studies have considered variables in the school environment as possible correlates of sexting. In this regard, the present study has relevant research implications as it confirms the importance of taking into account the roles of family and schooling variables. Our study examined as many as five variables concerning the school context: the type of school, being new to the school, repetition of a grade, and academic expectations in Math and in Spanish. Our data indicates that repeating a grade was statistically associated with sending sexts. Regarding academic aspects, Baumgartner et al. (2012) were the first to warn that adolescents with lower educational performance were more likely to experience moderate risk situations on the internet, including sexting. On the contrary, Bauermeister et al. (2014) found that adolescents with a higher educational level practiced more sexting, although it is likely that the educational level is modulated by age, which this study suggests is a differentiating variable for whether adolescents are involved in sexting or not. In other studies, academic performance was not found to influence sexting (Benotsch 
et al., 2013; Yeung et al., 2014). In our study, the educational level was operationalized in the form of respondents' expectations of academic performance in the subjects of Math and Spanish, suggesting that adolescents with low expectations of academic performance in Math were more likely to have forwarded sexts. In agreement, the study carried out by Baumgartner et al. (2012) implied that low academic performance was not only a predictor of participation in sexting but also of a diverse range of online and offline sexual risk behaviors. Although our findings concur that academic variables may be relevant markers or indicators of participation in sexting, evidently more research is needed to clarify the predictive power of such variables.

Regarding the family situation of adolescents, research in this field underlines the importance of the relationship between parents and children. Our study suggests that living in a single-parent family environment was associated with an increased likelihood of having received sexts, while Dake et al. (2012), Vanden Abeele et al. (2014), and Chaudhary et al. (2017) obtained similar results, detecting a significant increase in involvement in sexting in children of divorced or separated parents. Research by Baumgartner et al. (2012) also suggested that adolescents from less cohesive families were more likely to participate in situations of moderate risk relating to the use of the internet, including involvement in sexting. It is possible that adolescents living in a single-parent family environment have less support when it comes to discussing issues as important as the self-management of intimate and sexual relationships. Indeed, some studies suggest that adolescents who perceive low levels of practical and emotional support from their families are more likely to send sexts (Burén \& Lunde, 2018; Campbell \& Park, 2014). Such findings highlight the connection between the parent-adolescent relationship and online sexual practices, a connection that merits further exploration.

\section{Implications for Future Research}

Based on the results of the present study and the scope of sexting practice in general, various suggestions for future research may be formulated for a better understanding of this topic. Considering that the most exchanged sext format in our sample was that of images, and that the consequences of the malicious use of pictures or videos in which one is easily identifiable or recognizable may be particularly harmful, future research should clarify the importance of whether or not the faces of participants are visible in the pictures or videos. Already several studies have indicated that a significant proportion of participants reporting having sent nude and seminude depictions admitted having included faces in such depictions (Perkins, Becker, Tehee, \& Mackelprang, 2014; Crimmins \& Seigfried-Spellar, 2014).
Our study suggests that living in a single-parent family was associated with higher sexting rates. Further research is needed to explore how family dynamics, including educational and communication styles, emotional attachment, and parental control strategies, can influence sexting practice among youths. For instance, it has already been suggested that some parental strategies to control and monitor sexting are largely ineffective (Campbell \& Park, 2014). Such research would help the development of practical advice for parents regarding their roles in their children's sex education in the digital sphere.

Regarding schooling aspects, we analyzed performance expectations in the school subjects of Math and Spanish in relation to sexting. In future research, it would be interesting to further explore whether better social and communicative skills, associated with better performance in language subjects, contribute to increased involvement in sexting (see Woodward et al., 2017). It is, indeed, possible that adolescents with better communication skills send and receive more sexts, as some studies have already suggested that personality factors, such as extraversion (Olatunde \& Balogun, 2017; Delevi $\&$ Weisskirch, 2013), are related to the prevalence of sexting.

Regarding the potential implementation of educational measures in schools to inform students about the phenomenon of sexting, our findings provide support for further consideration of such measures, as $70 \%$ of our respondents considered such measures necessary. Research already recommends that such measures should revolve around four fundamental principles. Firstly, as Bianchi et al. (2017) point out, education in this area should provide detailed information on the innate characteristics of actions committed on the internet: the potential for a considerable and widespread audience, the possibility of acting under anonymity or not, the imperishability of or difficulty to eliminate content, the ease of modification and distribution of content without any control (Chalfen, 2009; Dake et al., 2012; Patrick et al., 2015). Secondly, educational measures should address the opportunities, risks, and consequences of the specific practice of sexting (Yeung et al., 2014), and provide information on cyber-victimization under the guises of sextortion, grooming, cyberbullying, and revenge pornography. Thirdly, considering that sexting relates to the intimacy and sexual development of young people, information on ethical issues, such as willingness and consensus when exchanging of sexually natured messages between sender and receiver, could be useful (Albury \& Crawford, 2012; Patrick et al., 2015). Fourthly, given the relational nature of sexting, and as a consequence of the above, training and reinforcement of assertive skills in adolescents could be useful in dealing with pressure to send sexts (Choi et al., 2016; GámezGuadix \& Mateos-Pérez, 2019; Gregg et al., 2018).

Beyond educational measures, accessible and appropriate legal measures should also be introduced with respect to sexting incidents (Van Ouytsel, Walrave, \& Van Gool, 
2014). Approximately $41 \%$ of our sample believed that the contents of sexts received were intended to harm their protagonists. For this reason, professionals directly involved in adolescent development should also receive information and action guidelines on sexting and other possible online risk practices (Khubchandani, Telljohann, Price, Dake, \& Hendershot, 2013).

\section{Our Study's Limitations}

Our results must be interpreted within the context of the study's limitations. The cross-sectional nature of the study limits the establishment of causal relationships between the practice of sexting and the correlates analyzed. The development of longitudinal studies would, indeed, help to confirm our results, particularly in light of the fact that sexting practices may evolve with time and the advancement of information and communications technology. Furthermore, the study's sample was chosen for convenience, limiting its wider validity and the generalization of the data to other aspects, such as other educational levels. Additionally, answers provided by adolescents regarding sexting via the method of selfreporting may be influenced by social desirability effects (Hudson \& Fetro, 2015; Livingstone \& Görzig, 2012). Finally, although our work provided more detailed information on adolescent sexting practices, developing its questions to respondents based on previous study instruments and on the results of a discussion group, the lack of a standardized definition or set of measures of sexting still makes it challenging to accurately estimate or find consensus on its prevalence.

\section{Conclusions}

Our study suggests that sexting is prevalent among Spanish secondary school students: over $60 \%$ of our sample had been involved in some sort of sexting (24\% of respondents had sent a sext, $58 \%$ had received one, and $18 \%$ had forwarded one).

The most exchanged sexting contents in our sample were in image and video formats, were received mainly through oneto-one channels, and featured adolescent protagonists known personally by and of the opposite sex to respondents. Although only $40 \%$ of our study sample believed that the sexts exchanged had been intended to harm their protagonists, more than $70 \%$ thought it necessary to implement educational measures at their school to inform them about the potential negative consequences of the practice of sexting. This is particularly important in light of the fact that $18 \%$ of our sample had forwarded a sext to others and that sexts received exclusively via group channels most often featured protagonists that were peers of the same sex as the recipient. These results suggest that the phenomenon of sexting was far from being a consensual and private sexual practice between two individuals.

The socio-demographic, family, and educational profiling of adolescents most involved in sexting experiences indicates that those who had sent sexts were more likely to have repeated a grade and to report using a greater number of social media platforms on a more frequent basis. Certain subgroups of the students, including males, older adolescents, those living in a single-parent family, those reporting use of a greater number of social media platforms, and those spending more time using technological communication devices and social media platforms, were significantly more likely to have received sexts. Those reporting to have forwarded sexts were more likely to be male, to be older, to use a greater number of social media platforms, and to have low performance expectations in the school subject of Math. Finally, our study also provides results that can support new lines of inquiry into analyzing the relationship between sexting and certain socio-demographic, family situation, and educational variables in relation to adolescents.

Acknowledgments We are grateful to the young people who participated in our research, as well as to the schools that allowed us to administer our questionnaire.

Funding This work was supported by funding from the Government of the Valencian Community (predoctoral grant DOGV No. 7943, ACIF, 2017) and from the Spanish Ministry of Science, Innovation and Universities (PGC2018-100675-B-I00). Funders had no role in the study design, data collection or analysis, the decision to publish, or the preparation of the manuscript.

\section{Compliance with Ethical Standards}

Conflict of Interest The authors declare that they have no conflict of interest.

Ethical Approval The authors received due ethical approval for all research conducted in this study.

Data Sharing The datasets generated and analyzed in this study are not publicly available, but are available from the corresponding author on reasonable request.

\section{References}

Albury, K., \& Crawford, K. (2012). Sexting, consent and young people's ethics: Beyond Megan's story. Journal of Media \& Cultural Studies, 26, 463-473. https://doi.org/10.1080/10304312.2012.665840.

Barrense-Dias, Y., Berchtold, A., Suris, J. C., \& Akre, C. (2017). Sexting and the definition issue. Journal of Adolescent Health, 61(5), 544 554. https://doi.org/10.1016/j.jadohealth.2017.05.009.

Bauermeister, J., Yeagley, E., Meanley, S., \& Pingel, E. (2014). Sexting among young men who have sex with men: Results from a national survey. Journal of Adolescent Health, 54(5), 606-611. https://doi. org/10.1016/j.jadohealth.2013.10.013. 
Baumgartner, S., Sumter, S. R., Peter, J., \& Valkenburg, P. (2012). Identifying teens at risk: Developmental pathways of online and offline sexual risk behavior. Pediatrics, 130(6), e1489-e1496. https://doi.org/10.1542/peds.2012-0842.

Baumgartner, S. E., Sumter, S. R., Peter, J., Valkenburg, P. M., \& Livingstone, S. (2014). Does country context matter? Investigating the predictors of teen sexting across Europe. Computers in Human Behavior, 34, 157-164. https://doi.org/10.1016/j.chb.2014.01.041.

Benotsch, E. G., Snipes, D. J., Martin, A. M., \& Bull, S. S. (2013). Sexting, substance use, and sexual risk behaviour in young adults. Journal of Adolescent Health, 52(3), 307-313. https://doi.org/10. 1016/j.jadohealth.2012.06.011.

Bianchi, D., Morelli, M., Baiocco, R., \& Chirumbolo, A. (2017). Sexting as the mirror on the wall: Body-esteem attribution, media models, and objectified-body consciousness. Journal of Adolescence, 61, 164-172. https://doi.org/10.1016/j.adolescence.2017.10.006.

Bianchi, D., Morelli, M., Baiocco, R., \& Chirumbolo, A. (2019). Individual differences and developmental trends in sexting motivations. Current Psychology, 1-10. https://doi.org/10.1007/s12144019-00398-4.

Branch, K., Hilinski-Rosick, C., Johnson, E., \& Solano, G. (2017). Revenge porn victimization of college students in the United States: An exploratory analysis. International Journal of Cyber Criminology, 11(1), 128-142. https://doi.org/10.5281/zenodo. 495777.

Burén, J., \& Lunde, C. (2018). Sexting among adolescents: A nuanced and gendered online challenge for young people. Computers in Human Behavior, 85, 210-217. https://doi.org/10.1016/j.chb.2018. 02.003

Burkett, M. (2015). Sex(t) talk: A qualitative analysis of young adults' negotiations of the pleasures and perils of sexting. Sexuality and Culture, 19(4), 835-863. https://doi.org/10.1007/s12119-0159295-0.

Campbell, S. W., \& Park, Y. J. (2014). Predictors of mobile sexting among teens: Toward a new explanatory framework. Mobile Media \& Communication, 2(1), 20-39. https://doi.org/10.1177/ 2050157913502645.

Chalfen, R. (2009). It's only a picture: Sexting, 'smutty' snapshots, and felony charges. Visual Studies, 24(3), 258-268. https://doi.org/10. 1080/14725860903309203.

Chaudhary, P., Peskin, M., Temple, J. R., Addy, R. C., Baumler, E., \& Shegog, R. (2017). Sexting and mental health: A school based longitudinal study among youth in Texas. Journal of Applied Research on Children: Informing Policy for Children at Risk, 8(1), 1-27.

Choi, H., Van Ouytsel, J., \& Temple, J. R. (2016). Association between sexting and sexual coercion among female adolescents. Journal of Adolescence, 53, 164-168. https://doi.org/10.1016/j.adolescence. 2016.10.005

Cooper, K., Quayle, E., Jonsson, L., \& Svedin, C. G. (2016). Adolescents and self-taken sexual images: A review of the literature. Computers in Human Behavior, 55, 706-716. https://doi.org/10.1016/.j.chb. 2015.10.003.

Cox Communications. (2009). Teen online and wireless safety survey: Cyberbullying, sexting, and parental controls. Available at: http:// www.scribd.com/doc/20023365/2009-Cox-Teen-Online-WirelessSafety-Survey-Cyberbullying-Sexting-and-Parental-Controls

Crimmins, D. M., \& Seigfried-Spellar, K. C. (2014). Peer attachment, sexual experiences, and risky online behaviors as predictors of sexting behaviors among undergraduate students. Computers in Human Behavior, 32, 268-275. https://doi.org/10.1016/j.chb.2013. 12.012 .

Dake, J. A., Price, D. H., Mazriaz, L., \& Ward, B. (2012). Prevalence and correlates of sexting behaviour in adolescents. American Journal of Sexuality Education, 7(1), 1-15. https://doi.org/10.1080/15546128. 2012.650959
Davis, M. J., Powell, A., Gordon, D., \& Kershaw, T. (2016). I want your sext: Sexting and sexual risk in emerging adult minority men. AIDS Education and Prevention, 28(2), 138-152. https://doi.org/10.1521/ aeap.2016.28.2.138.

Delevi, R., \& Weisskirch, R. S. (2013). Personality factors as predictors of sexting. Computers in Human Behavior, 29(6), 2589-2594. https://doi.org/10.1016/j.chb.2013.06.003.

Döring, N. (2014). Consensual sexting among adolescents: Risk prevention through abstinence education or safer sexting? Cyberpsychology: Journal of Psychosocial Research on Cyberspace, 8(1), article 9. https://doi.org/10.5817/CP2014-1-9.

Drouin, M., Coupe, M., \& Temple, J. R. (2017). Is sexting good for your relationship? It depends... Computers in Human Behavior, 75, 749-756. https://doi.org/10.1016/j.chb.2017.06.018.

Drouin, M., Ross, J., \& Tobin, E. (2015). Sexting: A new, digital vehicle for intimate partner aggression? Computers in Human Behavior, 50, 197-204. https://doi.org/10.1016/j.chb.2015.04.001.

Drouin, M., \& Tobin, E. (2014). Unwanted but consensual sexting among young adults: Relations with attachment and sexual motivations. Computers in Human Behavior, 31, 412-418. https://doi.org/10. 1016/j.chb.2013.11.001.

Englander, E. (2015). Coerced sexting and revenge porn among teens. Bullying, Teen Aggression \& Social Media, 1, 19-21.

Gámez-Guadix, M., de Santisteban, P., \& Resett, S. (2017). Sexting among Spanish adolescents: Prevalence and personality profiles. Psicothema, 29(1), 29-34. https://doi.org/10.7334/ psicothema2016.222.

Gámez-Guadix, M., \& Mateos-Pérez, E. (2019). Longitudinal and reciprocal relationships between sexting, online sexual solicitations, and cyberbullying among minors. Computers in Human Behavior, 94, 70-76. https://doi.org/10.1016/j.chb.2019.01.004.

Gámez-Guadix, M., \& Santisteban, P. (2018). "Sex Pics?”: Longitudinal predictors of sexting among adolescents. Journal of Adolescent Health, 63, 608-614. https://doi.org/10.1016/j.jadohealth.2018.05. 032.

Gassó, A., Klettke, B., Agustina, J., \& Montiel, I. (2019). Sexting, mental health, and victimization among adolescents: A literature review. International Journal of Environmental Research and Public Health, 16(13), 2364. https://doi.org/10.3390/ijerph16132364.

Gordon-Messer, D., Bauermeister, J. A., Grodzinski, A., \& Zimmerman, M. (2013). Sexting among young adults. Journal of Adolescent Health, 52(3), 301-306. https://doi.org/10.1016/j.jadohealth.2012. 05.013 .

Gregg, D., Somers, C. L., Pernice, F. M., Hillman, S. B., \& Kernsmith, P. (2018). Sexting rates and predictors from an urban midwest high school. Journal of School Health, 88(6), 423-433. https://doi.org/ 10.1111/josh.12628.

Hair, J. F., Black, B., Babin, B., \& Anderson, R. E. (2010). Multivariate data analysis (7th ed.). Upper Saddle River, NJ: Pearson.

Hinduja, S. \& Patchin, J.W. (2010). Sexting: A brief guide for educators and parents. Cyberbullying research center. Available at: www. cyberbullying.us/Sexting_Fact_Sheet.pdf

Houck, C. D., Barker, D., Rizzo, C., Hancock, E., Norton, A., \& Brown, L. K. (2014). Sexting and sexual behavior in at-risk adolescents. Pediatrics, 133(2), 276-282. https://doi.org/10.1542/peds.20131157.

Hudson, H. K., \& Fetro, J. V. (2015). Sextual activity: Predictors of sexting behaviors and intentions to sext among selected undergraduate students. Computers in Human Behavior, 49, 615-622. https:// doi.org/10.1016/j.chb.2015.03.048.

Hudson, H. K., \& Marshall, S. A. (2016). Sexty southerners: Sexting content and behaviors among southern undergraduates. The Health Educator, 48(1), 34-43.

Kernsmith, P. D., Victor, B. G., \& Smith-Darden, J. P. (2018). Online, offline, and over the line: Coercive sexting among adolescent dating 
partners. Youth \& Society, 50(7), 891-904. https://doi.org/10.1177/ $0044118 X 18764040$.

Khubchandani, J., Telljohann, S. K., Price, J. H., Dake, J. A., \& Hendershot, C. (2013). Providing assistance to the victims of adolescent dating violence: A national assessment of school nurses' practices. Journal of School Health, 83(2), 127-136. https://doi. org/10.1111/josh.12008.

Klettke, B., Hallford, D. J., \& Mellor, D. J. (2014). Sexting prevalence and correlates: A systematic literature review. Clinical Psychology Review, 34(1), 44-53. https://doi.org/10.1016/j.cpr.2013.10.007.

Lenhart, A. (2009). Teens and sexting: How and why minor teens are sending sexually suggestive nude or nearly nude images via text messages. Washington, DC: Pew Internet \& American Life Project. Available at: http://www.pewinternet.org/files/old-media/ Files/Reports/2009/PIP_Teens_and_Sexting.pdf.

Lim, M. S., Vella, A. M., Horyniak, D. R., \& Hellard, M. E. (2016). Exploring attitudes towards sexting of young people: A crosssectional study. Sexual Health, 13(6), 530-535. https://doi.org/10. 1071/SH16029.

Lippman, J. R., \& Campbell, S. W. (2014). Damned if you do, damned if you don't...if you're a girl: Relational and normative contexts of adolescent sexting in the United States. Journal of Children and Media, 8(4), 371-386. https://doi.org/10.1080/17482798.2014. 923009.

Little, R. J., \& Rubin, D. (2002). Statistical analysis with missing data (2nd ed.). New York: Wiley.

Livingstone, S., \& Görzig, A. (2012). Sexting. In S. Livingstone, L. Haddon, \& A. Görzig (Eds.), Children, risk and safety on the internet: Research and policy challenges in comparative perspective (pp. 151-164). Bristol: The Policy Press.

Lloria, P. (2013). Delitos y redes sociales: los nuevos atentados a la intimidad, el honor y la integridad moral. Especial referencia al «sexting». Wolters Kluwer Revistas, 1-12.

Madigan, S., Ly, A., Rash, C. L., Van Ouytsel, J., \& Temple, J. R. (2018). Prevalence of multiple forms of sexting behavior among youth: A systematic review and meta-analysis. JAMA Pediatrics, 172(4), 327-335. https://doi.org/10.1001/jamapediatrics.2017.5314.

Martínez-Prather, K., \& Vandiver, D. M. (2014). Sexting among teenagers in the United States: A retrospective analysis of identifying motivating factors, potential targets, and the role of a capable guardian. International Journal of Cyber Criminology, 8(1), 21-35.

Mitchell, K. J., Finkelhor, D., Jones, L. M., \& Wolak, J. (2012). Prevalence and characteristics of youth sexting: A national study. Pediatrics, 129(1), 13-20. https://doi.org/10.1542/peds.2011-1730.

Morelli, M., Bianchi, D., Baiocco, R., Pezzuti, L., \& Chirumbolo, A. (2016a). Not-allowed sharing of sexts and dating violence from the perpetrator's perspective: The moderation role of sexism. Computers in Human Behavior, 56, 163-169. https://doi.org/10. 1016/j.chb.2015.11.047.

Morelli, M., Bianchi, D., Baiocco, R., Pezzuti, L., \& Chirumbolo, A. (2016b). Sexting, psychological distress and dating violence among adolescents and young adults. Psicothema, 28(2), 137-142. https:// doi.org/10.7334/psicothema2015.193.

Olatunde, O., \& Balogun, F. (2017). Sexting: Prevalence, predictors, and associated sexual risk behaviours among postsecondary school young people in Ibadan, Nigeria. Frontiers in Public Health, 5(96), 1-8. https://doi.org/10.3389/fpubh.2017.00096.

Parker, T. S., Blackburn, K. M., Perry, M. S., \& Hawks, J. M. (2013). Sexting as an intervention: Relationship satisfaction and motivation considerations. The American Journal of Family Therapy, 41(1), 112. https://doi.org/10.1080/01926187.2011.635134.

Patrick, K., Heywood, W., Pitts, M., \& Mitchell, A. (2015). Demographic and behavioural correlates of six sexting behaviours among Australian secondary school students. Sexual Health, 12, 480-487. https://doi.org/10.1071/SH15004.
Perkins, A. B., Becker, J. V., Tehee, M., \& Mackelprang, E. (2014). Sexting behaviors among college students: Cause for concern? International Journal of Sexual Health, 26(2), 79-92. https://doi. org/10.1080/19317611.2013.841792.

Reyns, B. W., Henson, B., \& Fisher, B. S. (2014). Digital deviance: Low self-control and opportunity as explanations of sexting among college students. Sociological Spectrum, 34, 273-292. https://doi.org/ 10.1080/02732173.2014.895642.

Rice, E., Craddock, J., Hemler, M., Rusow, J., Plant, A., Montoya, J., \& Kordic, T. (2018). Associations between sexting behaviors and sexual behaviors among mobile phone-owning teens in Los Angeles. Child Development, 89(1), 110-117. https://doi.org/10.1111/cdev. 12837.

Rice, E., Gibbs, J., Winetrobe, H., Rhoades, H., Plant, A., Montoya, J., \& Kordic, T. (2014). Sexting and sexual behaviour among middle school student in Los Angeles. Pediatrics, 134(1), 21-28. https:// doi.org/10.1542/peds.2013-2991.

Rice, E., Rhoades, H., Winetrobe, H., Sanchez, M., Montoya, J., Plant, A., \& Kordic, T. (2012). Sexually explicit cell phone messaging associated with sexual risk among adolescents. Pediatrics, 130(4), 667-673. https://doi.org/10.1542/peds.2012-0021.

Ricketts, M. L., Maloney, C., Marcum, C. D., \& Higgins, G. E. (2015). The effect of Internet related problems on the sexting behaviors of juveniles. American Journal of Criminal Justice, 40(2), 270-284. https://doi.org/10.1007/s12103-014-9247-5.

Stanley, N., Barter, C., Wood, M., Aghtaie, N., Larkins, C., Lanau, A., \& Overlien, C. (2018). Pornography, sexual coercion and abuse and sexting in young people's intimate relationships: A European study. Journal of Interpersonal Violence, 33(19), 2919-2944. https://doi. org/10.1177/0886260516633204.

Strassberg, D., McKinnon, R., Sustaíta, M., \& Rullo, J. (2013). Sexting by high school students: An exploratory and descriptive study. Archives of Sexual Behavior, 42(1), 15-21. https://doi.org/10.1007/ s10508-012-9969-8.

Strassberg, D. S., Cann, D., \& Velarde, V. (2017). Sexting by high school students. Archives of Sexual Behaviour, 46(6), 1667-1672. https:// doi.org/10.1007/s10508-016-0926-9.

Temple, J. R., Paul, J. A., van den Berg, P., Le, V. D., McElhany, A., \& Temple, B. W. (2012). Teen sexting and its associations with sexual behaviours. Archives of Pediatrics and Adolescent Medicine, 166(9), 828-833. https://doi.org/10.1001/archpediatrics.2012.835.

The National Campaign to Prevent Teen and Unplanned Pregnancy (2008). Sex and tech: Results from a survey of teens and young adults. Available at: https://thenationalcampaign.org/sites/default/ files/resource-primary-download/sex_and_tech_summary.pdf.

Van Ouytsel, J., Lu, Y., Ponnet, K., Walrave, M., \& Temple, J. R. (2019). Longitudinal associations between sexting, cyberbullying, and bullying among adolescents: Cross-lagged panel analysis. Journal of Adolescence, 73, 36-41. https://doi.org/10.1016/j.adolescence. 2019.03.008

Van Ouytsel, J., Ponnet, K., \& Walrave, M. (2018). Cyber dating abuse victimization among secondary school students from a lifestyleroutine activities theory perspective. Journal of Interpersonal Violence, 33(7), 2767-2776. https://doi.org/10.1177/ 0886260516629390

Van Ouytsel, J., Ponnet, K., Walrave, M., \& d'Haenens, L. (2017). Adolescent sexting from a social learning perspective. Telematics and Informatics, 34, 287-298. https://doi.org/10.1016/j.tele.2016. 05.009 .

Van Ouytsel, J., Van Gool, E., Ponnet, K., \& Walrave, M. (2014). Brief report: The association between adolescents' characteristics and engagement in sexting. Journal of Adolescence, 37(8), 1387-1391. https://doi.org/10.1016/j.adolescence.2014.10.004.

Van Ouytsel, J., Walrave, M., \& Van Gool, E. (2014). Sexting: Between thrill and fear-How schools can respond. The Clearing House: A Journal of Educational Strategies, Issues and Ideas, 87, 204-212. 
Vanden Abeele, M., Campbell, S. W., Eggermont, S., \& Roe, K. (2014). Sexting, mobile porn use, and peer group dynamics: Boys' and girls' self-perceived popularity, need for popularity, and perceived peer pressure. Media Psychology, 17(1), 6-33. https://doi.org/10.1080/ 15213269.2013.801725.

Villacampa, C. (2017). Teen sexting: Prevalence, characteristics and legal treatment. International Journal of Law, Crime and Justice, 49, 10 21. https://doi.org/10.1016/j.ijlcj.2017.01.002.

Walker, J. T., \& Moak, S. (2010). Child's play or child pornography: The need for better laws regarding sexting. Academy of Criminal Justice Sciences Today, 35(1), 1-9. https://doi.org/10.1089/cyber.2018. 0291.

West, J. H., Lister, C. E., Hall, P. C., Crookston, B. T., Snow, P. R., Zvietcovich, M. E., \& West, R. P. (2014). Sexting among Peruvian adolescents. BMC Public Health, 14, 1-7. https://doi.org/10.1186/ 1471-2458-14-811.

Wolak, J., Finkelhor, D., Walsh, W., \& Treitman, L. (2018). Sextortion of minors: Characteristics and dynamics. Journal of Adolescent Health, 62(1), 72-79. https://doi.org/10.1016/j.jadohealth.2017.08. 014.
Wood, M., Barter, C., Stanley, N., Aghtaie, N., \& Larkins, C. (2015). Images across Europe: The sending and receiving of sexual images and associations with interpersonal violence in young people's relationships. Children and Youth Services Review, 59, 149-160. https:// doi.org/10.1016/j.childyouth.2015.11.005.

Woodward, V. H., Evans, M., \& Brooks, M. (2017). Social and psychological factors of rural youth sexting: An examination of genderspecific models. Deviant Behavior, 38(4), 461-476. https://doi.org/ 10.1080/01639625.2016.1197020.

Ybarra, M. L., \& Mitchell, K. J. (2014). "Sexting" and its relation to sexual activity and sexual risk behavior in a national survey of adolescents. Journal of Adolescent Health, 55(6), 757-764. https://doi. org/10.1016/j.jadohealth.2014.07.012.

Yeung, T. H., Horyniak, D. R., Vella, A. M., Hellard, M. E., \& Lim, M. S. C. (2014). Prevalence, correlates and attitudes towards sexting among young people in Melbourne, Australia. Sexual Health, 11(4), 332-339. https://doi.org/10.1071/SH14032.

Publisher's Note Springer Nature remains neutral with regard to jurisdictional claims in published maps and institutional affiliations. 